\title{
Work Productivity \\ as a Function of the Percentage of Monetary Incentives to Base Pay
}

\author{
Carol J. Frisch \\ Alyce M. Dickinson
}

SUMMARY. In many individual monetary incentive systems workers receive an hourly base pay and can earn incentives when productivity exceeds a specified standard. The total amount that can be earned in incentives is often expressed as a percentage of base pay. This study examined the effects of different percentages of incentive pay to base pay on work productivity. Seventy-five college students were randomly assigned to one of five incentive/base pay conditions: $0 \%$ (no incentives), $10 \%, 30 \%, 60 \%$ or $100 \%$. Subjects participated in 15 forty-five minute sessions during which they assembled parts made from bolts, nuts and washers. Subjects received a base pay amount for assembling a minimum of 50 quality parts per session and a per piece incentive for parts over 50 . If subjects assembled 120 quality parts, the production maximum, the total amount they could earn in incentives equaled $0 \%, 10 \%, 30 \%, 60 \%$ or $100 \%$ of their base pay. Results indicated that the productivity of subjects

Carol J. Frisch, MA, is affiliated with Performance Enterprises, 3180 Chestnut Hill Drive, \#301, Kalamazoo, Ml 49009. Alyce M. Dickinson, PhD, is affiliated with the Department of Psychology, Western Michigan University, Kalamazoo, MI 49008-5052. Requests for reprints should be addressed to Alyce M. Dickinson, $\mathrm{PhD}$, at the address mentioned above.

This study was conducted as the doctoral dissertation of the first author. The following individuals served as research assistants and their help, dedication, and scholarly contributions are gratefully acknowledged: C. Annese, D. Avery, S. Brawer, P. Desotell, D. Dysinger, R. Flaspohler, K. Gillette, J. Gorgone, J. Hampel, N. Hansen, G. Henry, J. Hoyer, J. Kotarak, K. Kopp, D. Leeger, A. Linklater, T. Mason, J. Miller, L. Nolan, S. Oah, K. Skaggs, S. Smith, and C. Turla. 
in the $10 \%, 30 \%, 60 \%$ and $100 \%$ groups was significantly greater than that of subjects in the $0 \%$ incentive group; however, the productivity of subjects in the $10 \%, 30 \%, 60 \%$ and $100 \%$ incentive groups did not differ.

Monetary incentives have increased employee productivity in comparison to hourly pay in both applied and laboratory settings (e.g., Bushhouse, Feeney, Dickinson, \& O’Brien, 1982; Farr, 1976; Gaetani, Hoxeng, \& Austin, 1985; Nebeker \& Neuberger, 1985; Orphen, 1982; Terborg \& Miller, 1978; Yukl, Wexley, \& Seymore, 1972). In applied settings, the increases have often been quite large. For example, Jenkins and Gupta (1982) stated that incentive systems have increased productivity by several hundred percent in a number of organizations, Vough (1979) indicated that they have resulted in a 200 percent increase in productivity over a ten year period at IBM, and Dierks and McNally (1987, March) have reported productivity increases of $200-300 \%$ at Union National Bank in Little Rock, Arkansas. Lincoln Electric, in Cleveland, Ohio, has implemented what is perhaps the most renowned incentive system; a system that combines piece-work pay with a meritbased profit sharing plan. Lincoln's workers are three times more productive than workers in comparable industries (Perry, 1988, December, 19). Further, although these workers are the highest paid workers in any factory in the world in similar lines of work, they are also, based on the units of work produced, the lowest cost workers (Henderson, 1985).

In addition to favorable comparisons with hourly pay, productivity increases that result from incentive systems also compare favorably with the results of other types of popular management systems. For example, Locke (1982) concluded, based on a review of the experimental literature, that monetary incentives increased productivity considerably more than goal setting, employee participation and job enrichment.

Due to their success, many organizations have begun to replace or supplement hourly wage systems with incentive systems. A recent survey by the American Productivity Center revealed that $75 \%$ of the 1600 responding organizations currently had some type of pay-for-performance plan and, of those plans, $80 \%$ had been imple- 
mented in the previous five years (O'Dell, 1986). Further, discussions of such plans have appeared with increasing frequency in popular business publications such as the Wall Street Journal, Fortune, Inc., the Harvard Business Review, and the Personnel Administrator (Dierks \& McNally, 1987, March; Dolan, 1985, November 15; Kantor, 1987, March-April; Kohn, 1988, January; Murray, 1987, April 28; O’Dell, 1986; Perry, 1988, December 19; Skryzcki, 1987, May 24).

Some, however, remain suspicious about the effectiveness of performance-contingent pay in spite of reported successes. Most of the concerns relate to design and implementation problems such as determining the appropriate mix of base pay and incentives, establishing fair standards upon which to base incentives, ascertaining the amount of incentives that will affect performance, determining the appropriateness of incentives when employees have little control over their own performance, and determining how frequently incentives must be provided in order for them to be effective (Lawler, 1971; Kesselman, Wood \& Hagen, 1974; Kopelman, 1983, October; Mihal, 1983, October). Such concerns are certainly legitimate, for in spite of the numerous discussion articles and reported successes, incentive technology has preceded scientific knowledge. Few experimental studies have examined the best way to design and implement incentive systems. The purpose of the present study was to examine one design issue: the optimum percentage of incentive pay to base pay.

In many individual monetary incentive systems, workers receive an hourly base salary and may earn additional money in incentives depending upon their performance. The amount of money that can be earned in incentives is usually expressed as a percentage of the base pay. For example, if workers are able to earn $30 \%$ of their base salary in incentives, and have a base salary of $\$ 10.00$ an hour, then they could earn an additional $\$ 3.00$ per hour depending upon performance. If the total amount of pay (base pay plus incentives) that can be earned is held constant, as the percentage of incentive pay to base pay increases the proportion of the workers' total pay that is incentive-based also increases. To illustrate this point, assume that the workers in the previous example are still able to earn a total of $\$ 13.00$ an hour but the percentage of incentive pay to base pay is 
$100 \%$ rather than $30 \%$. The workers would receive a base salary of $\$ 6.50$ per hour and could earn $100 \%$ of their base pay, or $\$ 6.50$, in incentives per hour. In the $30 \%$ incentive to base pay condition, $23 \%$ of the workers' total pay would be incentive-based ( $\$ 3.00$ incentives $/ \$ 13.00$ total pay) whereas in the $100 \%$ incentive to base pay condition, $50 \%$ of their total pay would be incentive-based ( $\$ 6.50$ incentives $\$ 13.00$ total pay). Because the incentives are dependent upon performance (and the hourly base pay is not), the link between pay and productivity becomes stronger as the percentage of incentive pay to base pay increases. From a theoretical and logical standpoint, productivity should thus increase as the percentage of incentive pay to base pay increases. However, it is quite possible that an optimum effect may be achieved at lower values. Lower incentive/base pay percentages may provide workers with more predictable incomes and thus be more acceptable to them, particularly when incentives are initially introduced. Further, lower percentages of incentive pay could "cushion" employees against performance decreases that are outside of their control. From the organization's standpoint, lower percentages of incentive pay would make personnel labor costs easier to budget because a larger proportion of wages would be fixed.

Compensation experts have suggested that employees be given the opportunity to earn $30 \%$ of their base pay in incentives (Fein, 1970; Henderson, 1985). It is believed that worker productivity will not be greatly affected if the incentive potential is below $30 \%$ of base pay, nor will worker productivity increase significantly if the incentive potential is increased above $30 \%$. According to Fein (1970):

... it is found that as the incentive potential diminishes, greater numbers of employees lose interest in the plan. But the converse holds true only to about $30 \%$. Increasing the potential above $30 \%$ does not appreciably motivate employees to increase their physical efforts over what would have been exerted under a $30 \%$ plan. (p. 28)

However, this $30 \%$ figure is not empirically-based. Rather, during World War II, all new incentive plans and changes to existing in- 
centive plans had to be approved by the War Labor Board and this board ruled that a $30 \%$ incentive potential was fair and equitable (Fein, 1970). Therefore, in this country, the $30 \%$ incentive potential is based on historical practice. Many incentive payment systems in other countries also offer a $30 \%$ incentive potential; a fact that Fein also cited as support for the $30 \%$ incentive potential. The objective of the present study, as indicated earlier, was to examine the relationship between productivity and the percentage of incentive pay to base pay and to investigate the validity of Fein's assertions regarding the $30 \%$ incentive potential.

While studies investigating the relative effectiveness of different percentages of incentives to base pay would ideally be conducted in real work settings, few companies and employees would permit the systematic manipulation of these percentages in a manner that would meet scientific criteria for validity. Further, work productivity may be affected by a large number of variables that exist in the work place; variables that cannot be isolated and controlled. Balcazar, Shupert, Daniels, Mawhinney and Hopkins (1989) have recently noted the importance of analog research when such difficulties exist: "Simulation researchers can provide a great service to those working in the field if they study phenomena which are modeled from but cannot be effectively or economically evaluated in the field"' (p. 35). Because of the difficulty of conducting this research in a work setting, the current study was conducted in an experimental laboratory.

\section{METHOD}

\section{Subjects}

Subjects were 75 volunteer male and female college students who signed informed consent forms. They were recruited from sections of an introductory psychology course and thus were primarily freshmen. They did not receive course credit for their participation but were paid as described in subsequent sections. Subjects were free to withdraw from the study at any time. 


\section{Dependent Variable and Work Task}

The work task consisted of assembling parts made from bolts, nuts and washers. Red or black bands, approximately 1 inch in length, were painted on some of the washers. The nuts and washers were placed on the bolt in the following order: nut, washer with red band, washer with black band, washer with red band, nut, plain washer, nut. Quality was measured as follows: the correct order of washers and nuts on the bolt; the washers and nuts securely assembled; and the edges of the painted bands lined up on one side. The dependent variable was the number of quality parts assembled.

\section{Experimental Design and Conditions}

The independent variable was the percentage of incentive pay to base pay. Five incentive/base pay percentage values were examined: $0 \%$ (no incentives), $10 \%, 30 \%, 60 \%$ and $100 \%$. A betweengroup experimental design was adopted with fifteen subjects randomly assigned to each of the five conditions. Sessions lasted 45 minutes and each subject participated in 15 sessions.

Subjects received a base pay amount for assembling a minimum of 50 quality parts during the 45-minute session and a per piece incentive for quality parts in excess of 50. This 50-part minimum performance standard was determined through pilot research and represented one standard deviation below the mean performance of subjects who were paid a guaranteed base salary of $\$ 2.50$ for assembling the parts during 45 -minute sessions. Subjects were required to assemble a minimum number of parts to receive the base pay in order to more accurately simulate a real work setting in which employees must meet minimum performance levels or face employment termination.

If subjects assembled 120 quality parts during the session, the total amount they could earn in incentives equaled $0 \%, 10 \%, 30 \%$, $60 \%$, or $100 \%$ of their base pay. One hundred twenty was the maximum number of quality parts that could be assembled in 45 minutes as determined by pilot work in which subjects were paid incentives for assembling the parts during 45-minute sessions.

Subjects in the $0 \%$ incentive condition were able to earn a total of $\$ 4.00$ in base pay per session if they assembled a minimum of 50 
quality parts and subjects in the $10 \%, 30 \%, 60 \%$ and $100 \%$ incentive conditions were able to earn a total of $\$ 4.00$ in base pay plus incentives per session if they assembled 120 parts. Thus, the total amount of money that could be earned was held constant across groups. The differing incentive/base pay percentages were obtained by varying the proportions of the total amount of pay $(\$ 4.00)$ allocated to base pay and incentive pay. As the percentage of incentive pay to base pay increased, the proportion of the total pay allocated to base pay decreased and the proportion allocated to incentive pay increased. The amounts that could be earned in base pay and incentives for each condition are shown in Table 1.

As indicated earlier, subjects received a per piece incentive for quality parts in excess of 50. The per piece incentive for each condition was determined by dividing the total amount that could be earned in incentives for that condition by 70 parts (the 120-part maximum minus the 50-part minimum standard). For example, subjects in the $30 \%$ incentive/base pay condition could earn a total of $\$ .93$ in incentives if they assembled 120 parts. Ninety-three cents divided by 70 parts resulted in a per piece incentive of $\$ .013$. The per piece incentives for each of the five conditions are shown in Table 2.

While the maximum number of parts that could reasonably be assembled in a forty-five minute session was 120 , some subjects occasionally assembled more than 120 parts. If subjects assembled more than 120 parts during a session, they received the per piece incentive for each part in excess of 50, and thus earned more than $\$ 4.00$ in total pay.

TABLE 1. The Amount of Base Pay and Incentives Available Per Session for Each Incentive/Base Pay Percentage Condition

\begin{tabular}{lccccc}
\hline Condition & $0 x$ & $10 x$ & $30 x$ & $60 x$ & $100 x$ \\
\hline Base Pay & $\$ 4.00$ & $\$ 3.63$ & $\$ 3.07$ & $\$ 2.50$ & $\$ 2.00$ \\
Incentive & $\$ 0.00$ & $\$ 0.37$ & $\$ 0.93$ & $\$ 1.50$ & $\$ 2.00$ \\
Total & $\$ 4.00$ & $\$ 4.00$ & $\$ 4.00$ & $\$ 4.00$ & $\$ 4.00$ \\
\hline
\end{tabular}


TABLE 2. The Per Piece Incentive for Each Incentive/Base Pay Percentage Condition

\begin{tabular}{lccccc}
\hline Condition & $0 \times$ & $10 \times$ & $30 \times$ & $60 \times$ & $100 x$ \\
\hline Per Piece Incentive & $\$ 0.00$ & $\$ 0.005$ & $\$ 0.013$ & $\$ 0.021$ & $\$ 0.029$ \\
\hline
\end{tabular}

\section{Procedure}

Twenty-three undergraduate and graduate students served as experimenters. All experimenters participated in an individual prestudy training session designed to teach them how to conduct the experimental sessions and record subject data. In addition, experimenters were provided with job aids for all of the major experimental activities such as conducting the first session, conducting subsequent sessions, handling subject scheduling conflicts, disassembling the parts, recounting the parts for interobserver agreement checks, and conducting debriefing sessions. Weekly one-hour research meetings were conducted throughout the study to discuss experimental procedures and resolve any problems.

During the first session, experimenters read the following instructions to subjects.

The purpose of this research project is to study the effects of payment systems. During each session I will ask you to assemble widgets. This is a widget. The sessions will be timed and will last for 45 minutes. I will tell you when to start and at the end of 45 minutes I will tell you to stop. I will then count the number of good widgets that you assembled and I will pay you for this work. At this time, I will also record on the graph the number of good widgets that you assembled. You may look at this graph at any time before and/or after each session. Attached to this graph will be a "Widget Payment Schedule" that will let you know how much you will be paid for the number of good widgets that you produce. You may also look at this payment schedule at any time before and/or after each 
session. A receipt form will also be attached to this graph which you will be asked to sign each time that I pay you. At the end of this study, this form will go to the Accounting Office for purposes of our accounting for the research funds. If, during the session, you wish to take a break, there are magazines available. You can go to the rest room at any time or just leave your work station to take a break whenever you want to. Smoking is only allowed in the entry way of the building. You can also turn on the radio if you wish.

The payment schedule that was shown to subjects indicated the base pay, the per piece incentive for parts assembled over 50 and the total amount that could be earned in the session for assembling from 50 to 189 parts.

After the preceding instructions, experimenters described the experimental task and demonstrated how to assemble the parts. Subjects assembled five practice parts and the experimenters provided feedback on the quality of those parts. A model part was left in the experimental room. Before the experimenters started the session, they emphasized the minimum performance requirement and answered any questions. Prior to the remaining sessions, experimenter interactions with subjects were minimal.

At the end of each 45-minute session, in the presence of the subject, the experimenter counted the total number of assembled parts and the number of correctly assembled parts, and then explained why each incorrectly assembled part did not meet the quality standard. The experimenter plotted the number of correctly assembled parts on a graph and paid the subject the appropriate amount indicated on the payment schedule.

Experimenters were instructed to refrain from praising or criticizing subject performance. In an attempt to control the verbal interactions between the subjects and experimenters, all of the experimenters' interactions with subjects were tape recorded. Although these tapes were not formally analyzed, an informal analysis suggested that the experimenters were complying, to the extent possible, with the request to withhold social praise and criticism. 


\section{Interobserver Agreement}

At the end of each experimental session, the experimenter placed the parts in a box and attached the subject and session number. To assess the accuracy of the part-count, a second individual recounted the parts for $97 \%$ of the sessions. Interobserver agreement was calculated by dividing the total number of agreements by the total number of agreements and disagreements, and multiplying the result by 100 .

Because the parts had to be carried a considerable distance from the experimental rooms to the room in which they were recounted, some parts became loose in transport. If these parts conformed to the other quality criteria, they would be counted as good parts by the experimenter but as bad parts by the second counter, lowering interobserver agreement. Due to this problem, the number of loose parts was recorded by both the first and second observers, and if the counts differed by more than 5 the data were not included in the calculation of interobserver agreement.

Average weekly interobserver agreement was determined, plotted on a graph and discussed with the experimenters during the weekly research meetings. In addition, during the weekly research meetings, approximately 20 parts taken from actual experimental sessions were scored independently by all the experimenters. When disagreements occurred, the parts were reexamined and the reasons for the disagreements discussed. Interobserver agreement averaged $96 \%$ for the entire study.

\section{RESULTS}

Figure 1 displays the mean number of quality parts produced by session by incentive group. As can be seen from this figure, there was an obvious initial practice effect. Performance increased sharply for the first four sessions and then tapered off although, with the exception of the $0 \%$ group, performance continued to increase throughout the study. An analysis of variance was conducted to determine whether the number of quality parts assembled differed as a function of the percentage of incentive pay to base pay. In order to determine the effects of the incentive percentage on rela- 
tively stable performance, the analysis was conducted on the pooled group means of the last five sessions only. As can be seen from the source table provided in Table 3 , the results were significant at the .007 level. The performance means and standard deviations for the last five sessions for each incentive condition are presented in Table 4.

The data displayed in Table 4 and Figure 1 indicate that subjects in the $0 \%$ incentive group produced considerably fewer parts than subjects in the other four groups, accounting for the reported significance level. A visual analysis is sufficient to determine that no significant performance differences occurred between the other incentive groups.

Visual inspection of the data revealed that the performances of some subjects were atypical of the performances of other subjects in the group. Given the relatively small number of subjects per group (15), it was decided to exclude the atypical subject data and conduct another analysis for exploratory purposes. The data for all fifteen sessions for these subjects were excluded. No subject data were dropped from the $10 \%$ group, the data for one subject were dropped

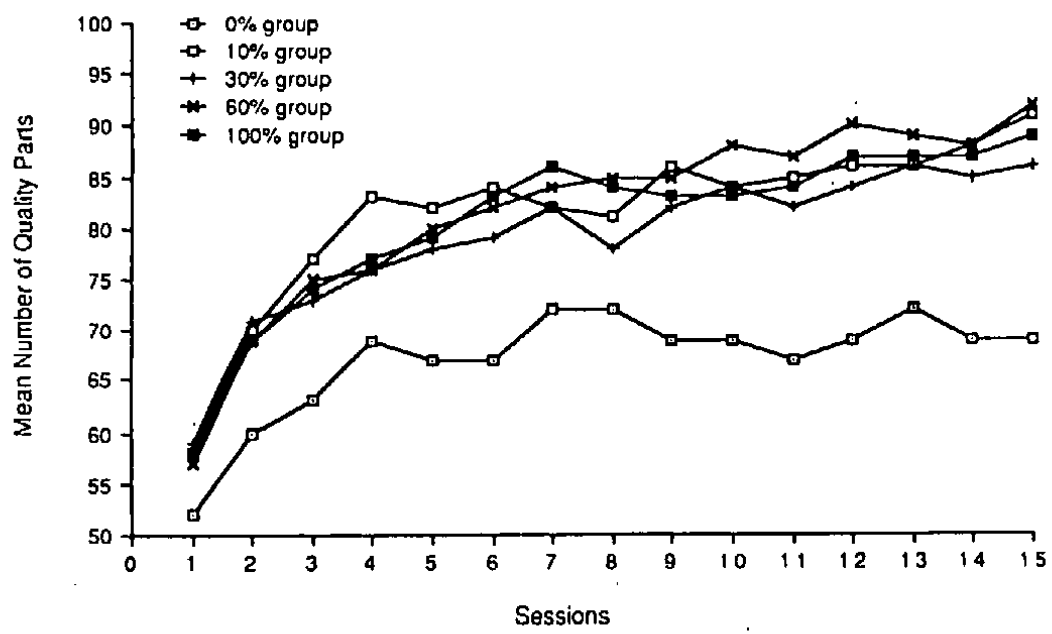

FIGURE 1. Mean number of quality parts assembled by session by incentive group. 
TABLE 3. Source Table for the Analysis of Variance Conducted on the Pooled Means of the Number of Quality Parts Assembled in the Last Five Sessions by Subjects in the Five Incentive/Base Pay Percentage Conditions

\begin{tabular}{lrrrrr}
\hline Source & DF & SS & MS & F & p \\
\hline Pactor & 4 & 4129 & 1032 & 3.84 & 0.007 \\
Error & 70 & 18808 & 269 & & \\
Total & 74 & 22936 & & & \\
\hline
\end{tabular}

TABLE 4. Performance Means and Standard Deviations for the Number of Quality Parts Assembled in the Last Five Sessions by Incentive/Base Pay Percentage Condition

\begin{tabular}{lccccc}
\hline Condition & $0 x$ & $10 x$ & $30 x$ & $60 x$ & $100 \times$ \\
\hline $\begin{array}{l}\text { Mean } \\
\text { Standard } \\
\text { Deviation }\end{array}$ & 68.7 & 87.2 & 84.5 & 88.7 & 87.4 \\
\hline
\end{tabular}

from each of the $30 \%$ and $60 \%$ groups, and the data for two subjects were dropped from each of the $0 \%$ and $100 \%$ groups. Figures 2 and 3 contrast the atypical subject performances that were excluded from the exploratory analysis with the mean performances of the other group members. Figure 4 displays the mean number of quality parts assembled by session by incentive group with the atypical subject data removed. With the atypical subject data excluded, the productivity of the $10 \%$ and $30 \%$ groups was comparable as was the productivity of the $60 \%$ and $100 \%$ groups. Productivity of the $60 \%$ and $100 \%$ groups was slightly higher than the productivity of the $10 \%$ and $30 \%$ groups with an average difference of four parts per session. Although the mean difference of quality parts assembled is not large, performance began to separate in the sixth session with no overlap occurring in subsequent sessions. 

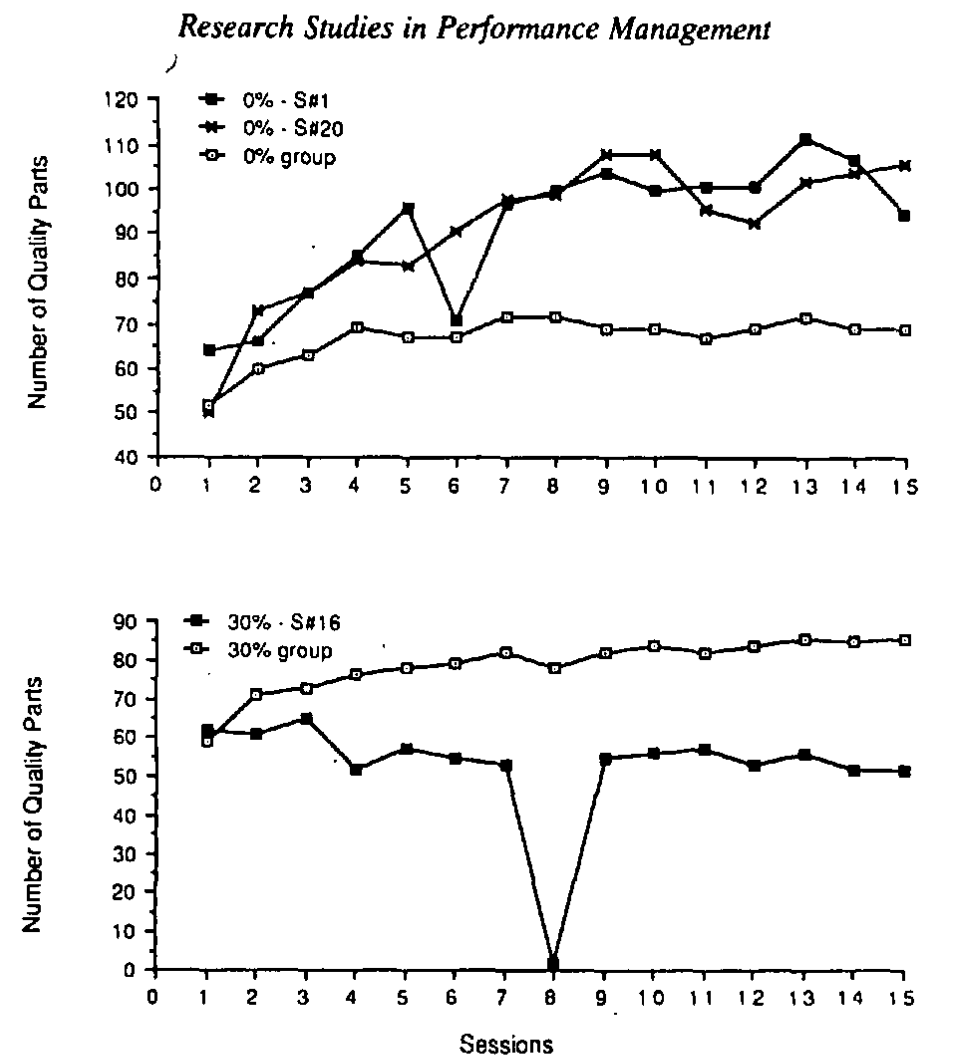

FIGURE 2. Atypical subject performance contrasted with the mean performance of subjects in the $0 \%$ and $30 \%$ incentive groups.

In addition to analyzing the number of quality parts assembled, the actual amount of money earned by subjects in each group was analyzed. Subjects in the $0 \%$ incentive group would earn a total of $\$ 4.00$ if they assembled a minimum of 50 quality parts during the session. If subjects in the $10 \%, 30 \%, 60 \%$ and $100 \%$ conditions assembled the maximum number of parts possible, 120 , they would receive a total of $\$ 4.00$. However, if performance was below the maximum, subjects in the lower incentive percentage conditions would earn more money than subjects in the higher incentive percentage conditions for assembling the same number of parts because of the higher base pay. For example, if subjects in the $30 \%$ 

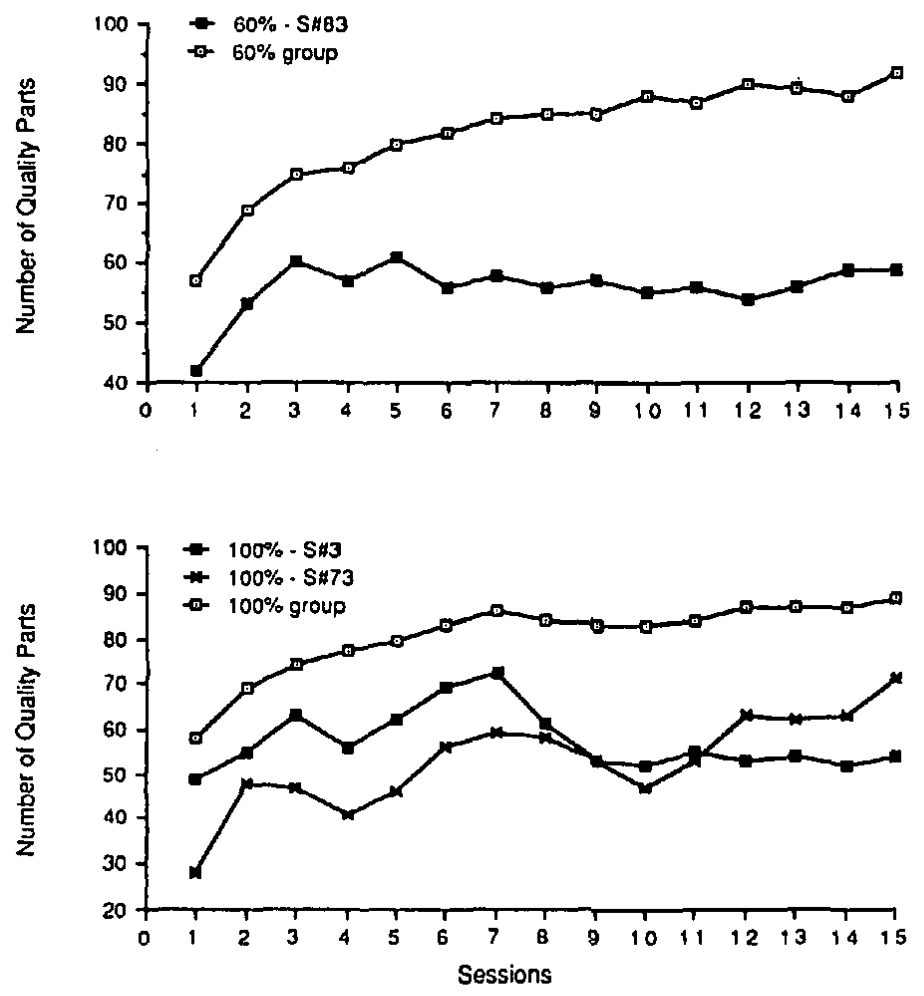

FIGURE 3. Atypical subject performance contrasted with the mean performance of subjects in the $60 \%$ and $100 \%$ incentive groups.

incentive condition assembled 85 parts, they would earn $\$ 3.07$ in base pay and $\$ .46$ in incentives for a total of $\$ 3.53$. Subjects in the $100 \%$ incentive condition who assembled 85 parts would earn $\$ 2.00$ in base pay and $\$ 1.02$ in incentives for a total of $\$ 3.02$.

Subjects did not typically assemble the maximum number of parts possible per session, and thus subjects in the $10 \%, 30 \%, 60 \%$ and $100 \%$ groups earned less than the $\$ 4.00$ total pay that was available per session. The mean pay earned by subjects by session is displayed in Figure 5. The atypical subject data are included in this analysis. As can be seen, there was an inverse relationship be- 
tween the total amount earned per session and the percentage of incentive to base pay, with subjects in the $0 \%$ group earning the most money and subjects in the $100 \%$ group earning the least. Therefore, these data, when combined with the performance data, indicate that subjects in the higher incentive/base pay percentage groups were making as many, or more parts for less money than subjects in the lower incentive/base pay percentage groups.

Because subjects did not typically assemble the maximum number of parts per session, 120 , they did not earn the total amount of money in incentives that was available. Since the incentive/base pay percentage values $(10 \%, 30 \%, 60 \%$ and $100 \%)$ were based on the total amount of money in incentives that could be earned, subjects did not actually earn $10 \%, 30 \%, 60 \%$ or $100 \%$ of their base pay in incentives. Rather, subjects in each group earned a smaller percentage of their base pay in incentives. To determine the percentage of base pay that subjects in a specific group actually earned in incentives, the average amount of money earned in incentives per session by subjects in that group was divided by the base pay. For example, subjects in the (planned) $10 \%$ incentive/base pay condi-

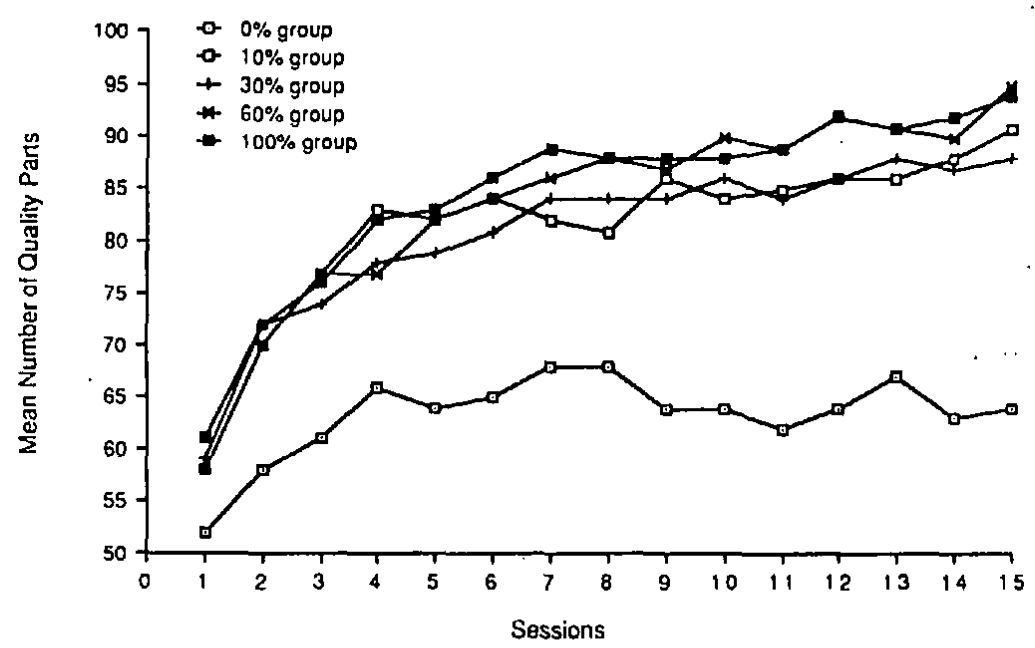

FIGURE 4. The mean number of quality parts assembled by session by incentive group with the atypical subject data excluded. 


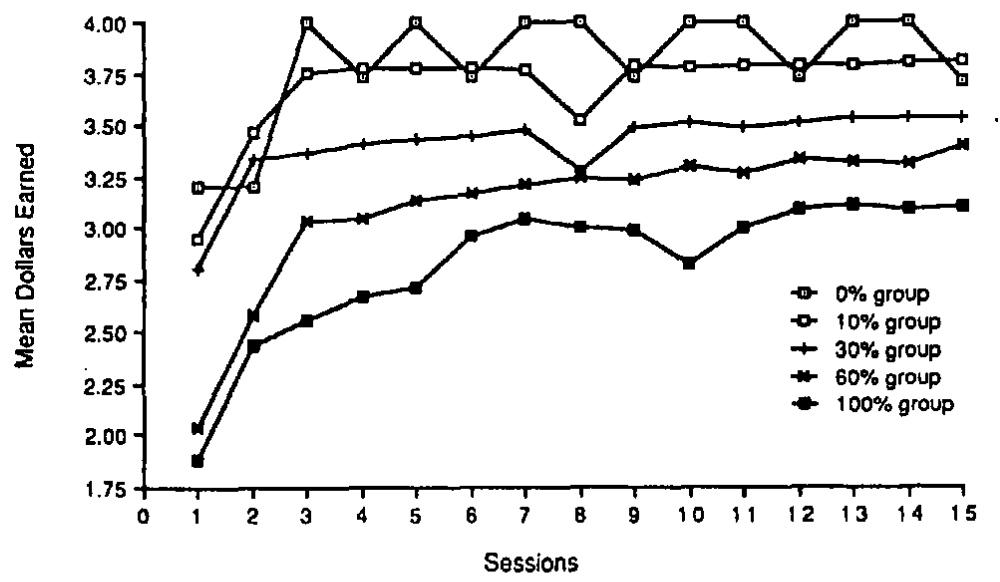

FIGURE 5. The mean pay earned by subjects by incentive group.

tion earned an average of $\$ .11$ per session in incentives. The base pay for this group was $\$ 3.63$. Therefore the percentage of base pay actually earned in incentives was 3\% (\$.11/\$3.63). Table 5 displays the planned percentages of incentive pay to base pay $(0 \%, 30 \%$, $60 \%$ and $100 \%$ ), the total amount of money per session that was available in incentives for each condition, the average amount of money per session actually earned in incentives by subjects in each condition, and the actual percentages of incentive pay to base pay. As can be seen, the actual percentages of incentive pay to base pay were considerably lower than the planned percentages of incentive pay to base pay. Subjects in the $10 \%, 30 \%, 60 \%$ and $100 \%$ conditions actually earned, on the average, only $3 \%, 13 \%, 25 \%$, and $54 \%$ of their base pay in incentives, respectively.

\section{DISCUSSION}

Consistent with previous research, monetary incentives resulted in significantly greater productivity than hourly pay. Subjects in the four incentive groups assembled an average of 17 to 20 parts more per session than subjects in the $0 \%$ incentive group. The productiv- 
TABLE 5. Planned Versus Actual Percentages of Incentive Pay to Base Pay

\begin{tabular}{|c|c|c|c|c|c|}
\hline $\begin{array}{l}\text { Planned Incentive/Base Pay } \\
\text { Percentages }\end{array}$ & $0 x$ & $10 x$ & $30 x$ & $60 x$ & $100 x$ \\
\hline $\begin{array}{l}\text { Total A mount of Incentives } \\
\text { Available per Session }\end{array}$ & $\$ 0.00$ & $\$ 0.37$ & $\$ 0.93$ & $\$ 1.50$ & $\$ 2.00$ \\
\hline $\begin{array}{l}\text { Average Amount of Incentives } \\
\text { Earned per Session }\end{array}$ & $\$ 0.00$ & $\$ 0.11$ & $\$ 0.39$ & $\$ 0.63$ & $\$ 1.08$ \\
\hline Base Pay per Session & $\$ 4.00$ & $\$ 3.63$ & $\$ 3.07$ & $\$ 2.50$ & $\$ 2.00$ \\
\hline $\begin{array}{l}\text { Actual Incentive/Base Pay } \\
\text { Percentages }\end{array}$ & $0 x$ & $3 x$ & $13 x$ & $25 x$ & $54 x$ \\
\hline
\end{tabular}

ity of subjects in the $10 \%, 30 \%, 60 \%$ and $100 \%$ incentive groups did not differ significantly.

Analysis of the amount of money earned by subjects revealed that the actual incentive percentages were considerably lower than those originally planned. The planned incentive percentages were based on maximum performance, assembling 120 parts per session. Data indicated that this maximum performance was indeed a "true" maximum: three subjects achieved or exceeded this maximum productivity and four others assembled over 110 parts per session during one or more sessions. However, most subjects never assembled this many parts and those that did only did so for a few sessions. Based on the average incentive amounts earned, the incentive percentages were actually $3 \%, 13 \%, 25 \%$ and $54 \%$ as opposed to $10 \%$, $30 \%, 60 \%$ and $100 \%$, respectively. Therefore, subjects in three of the incentive groups earned less than $30 \%$ of their base pay in incentives. Further, subjects in the $10 \%$ incentive group earned only $3 \%$ of their base salary in incentives. Yet, their performance, as well as the performance of subjects in the other three incentive groups, was considerably higher than the performance of subjects in the base pay group. These data strongly suggest, contrary to Fein's position (1970), that significant productivity improvements of a work group can be obtained with incentive potentials of less than $30 \%$. In fact, the size of the productivity improvement was quite 
surprising in the current study, given the relatively low base salaries of $\$ 3.63, \$ 3.07 . \$ 2.50$ and $\$ 2.00$ per session and hence the small amount of money actually earned in incentives.

Only subjects in the planned $100 \%$ incentive group actually earned more than $30 \%$ of their base pay in incentives. Significant incremental improvements in performance were not observed for this group, supporting Fein's (1970) position that higher incentive rates may not result in significant performance gains. However, an exploratory analysis conducted with atypical subject data excluded, suggested that higher incentive potentials might incrementally increase performance. No attempts were made to analyze the reasons for atypical performance which, in retrospect, was a mistake. For example, one subject reported that her roommate promised to buy her dinner if she assembled 110 parts during a session (which she did). Similar extraneous contingencies may have been responsible for other individual differences, differences that may have obscured the effects of the incentives due to the relatively small number of subjects within each group. When the atypical subject data were excluded, subjects who received $25 \%$ and $54 \%$ of their base pay in incentives assembled approximately four parts more per session than subjects who received $3 \%$ and $13 \%$ of their base pay in incentives. This performance difference began to occur in the sixth session and was maintained during the subsequent nine sessions. Therefore, although the mean performance differences were not significant, the data are sufficiently suggestive to merit further research with larger numbers of subjects or appropriate within-subject experimental designs.

Due to the analog nature of this study, the generality of the results to a work setting may, to some extent, be limited. Subjects worked in 45-minute sessions, and were exposed to the incentive conditions for only 15 sessions. Although the duration of exposure was longer than in any previous experimental study, work sessions were short and total exposure to the incentive conditions still approximated only two full work days. Longer work periods and/or prolonged exposure to the incentive conditions may yield different results. In addition, subjects worked in isolation, a rare event in the work place. Results from a study that examined the effects of group monetary contingencies on productivity (Stoneman \& Dickinson, 
1989) suggested that individual performance is influenced by the performance of other workers. Future research should examine how social factors influence productivity when workers receive individual monetary incentives, a topic that has not yet been systematically investigated.

Finally, subjects volunteered to participate in the study and could withdraw at any time. The money earned was discretionary income and therefore subjects could well afford to give it up. During the study, thirty subjects withdrew. Fourteen never, or only rarely, assembled the 50 parts needed to earn the base pay and, of these, eleven withdrew after the first session. Reported reasons for the other withdrawals included schedule conflicts, insufficient time to devote to academic studies, and "boredom" with the experimental task. In any event, workers would be more likely to remain with an organization and their performance may differ from that of subjects whose participation is more voluntary.

Subject satisfaction with the various percentages of incentive pay was not directly assessed in the present study. It is possible, however, that some subjects who withdrew from the study did so because of dissatisfaction with the incentive pay. Of the sixteen subjects who withdrew even though they consistently performed well enough to earn base pay, one withdrew from the base pay group while 3 or 4 withdrew from each of the incentive groups. However, because subjects in the incentive groups earned less money per session than subjects in the base pay group, the differences in withdrawal rates might have been due to the absolute amount earned rather than to the incentive pay arrangement.

The success of any performance management system depends not only on its effectiveness but also on its acceptability by workers. If incentive systems are unattractive to workers they will be hard to implement and maintain, may reduce the company's ability to compete effectively in the hiring market, and may increase absenteeism, turnover, and the number of grievances filed; factors that correlate highly with employee dissatisfaction. In the current study, all four of the incentive percentages -3\%,13\%,25\%, and 54\%-resulted in significant and comparable productivity increases in comparison to hourly pay. However, as indicated earlier, no attempts were made to determine what incentive potential subjects preferred. Fu- 
ture research should certainly do so. In a work setting, employees might favor lower rather than higher percentages of incentive pay because lower percentages increase the predictability of pay and "cushion" employees against performance decreases outside of their control. On the other hand, workers may prefer higher incentive potentials because pay would better reflect differences in individual work productivity and may, therefore, be perceived as more fair. Worker preference, as well as productivity, should be taken into consideration when determining the appropriate mix of incentive and base pay. Unfortunately, as pointed out by Mawhinney (1984) and Gupta (1980), preference data are not available to assist in that determination at this time.

\section{REFERENCES}

Balcazar, F. E., Shupert, M. K., Daniels, A. C., Mawhinney, T. C., Hopkins, B. L. (1989). An objective review and analysis of ten years of publication in the Joumal of Organizational Behavior Management. Joumal of Onganizational Behavior Management, 10, 7-37.

Bushhouse, F. E., Jr., Feeney, E. J., Dickinson, A. M., O’Brien, R. M. (1982). Increased productivity in man-paced and machine-paced performance. In $\mathbf{R}$. M. O'Brien and A. M. Dickinson (Eds.) Industrial Behavior Modification. New York: Pergamon Press.

Dierks, W., \& McNally, K. (1987, March). Incentives you can bank on. Personnel Administrator, pp. 61-65.

Dolan, C. (1985, November 15). Many companies now base workers' raises on their productivity. The Wall Street Joumal, pp. 1, 15.

Farr, J. L. (1976). Incentive schedules, productivity, and satisfaction in work groups. Organizational Behavior and Human Performance, 7, 159-170.

Fein, M. (1970). Wage incentive plans. Norcross, GA: American Institute of Industrial Engineers.

Gaetani, J. J., Hoxeng, D. D., \& Austin, J. T. (1985). Engineering compensation systems: Effects of commissioned versus wage payment. Joumal of Onganizational Behavior Management, 7, 51-63.

Gupta, N. (1980). Performance-contingent rewards and satisfaction. An initial analysis. Human Relations, 33, 813-829.

Henderson, R. I. (1985). Compensation management: Rewarding performance. Reston, VA: Reston.

Jenkins, G. D., \& Gupta, N. (1982). Financial incentives and productivity improvement. Joumal of Contemporary Business, 11, 43.56.

Kantor, R. M. (1987, March-April). The attack on pay. Harvard Business Review, pp. 60-67. 
Kesselman, G. A., Wood, M. T., \& Hagen, E. L. (1974). Relationship between performance and satisfaction under contingent and noncontingent reward system. Journal of Applied Psychology, 59, 374-376.

Kohn, A. (1988, January). Incentives can be bad for business. Inc., pp. 93-94.

Kopelman, R. E. (1983, October). Linking pay to performance is a proven management tool. Personnel Administrator, pp. 60-68.

Lawler, E. E., III. (1971). Pay and organizational effectiveness. New York: McGraw-Hill.

Locke, E. A. (1982). Employee motivation: A discussion. Joumal of Contemporary Business, $11,71-81$.

Mawhinney. T. C. (1984). Philosophical and ethical aspects of organizational behavior management: Some evaluative feedback. Jourmal of Organizational Behavior Management, 6, 5-31.

Mihal, W. L. (1983, October). Pay: more research is needed; goals may motivate better. Personnel Administrator, pp. 61-67.

Murray, A. (1987, April 28). Democrats latch on to bonus pay systems in search of new ideas. The Wall Street Journal, pp. 1, 24.

Nebeker, D. M., \& Neuberger, B. M. (1985). Productivity improvement in a purchasing division: The impact of a performance contingent reward system. Evaluation and Program Planning, 8, 121-134.

O'Dell, C. (1986). Major findings from people, performance and pay: A summary of a national survey on non-traditional reward and human resource practices. Houston: The American Productivity Center.

Orphen, C. (1982). The effects of contingent and noncontingent rewards on $\mathrm{cm}-$ ployee satisfaction and performance. The Joumal of Psychology, 110, 145 150.

Perry, N. J. (1988, December, 19). Here come richer, riskier pay plans. Fortune, p. 51-58.

Skryzcki, C. (1987, May 24). Linking wages with performance. The Washington Post, pp. H1, H3.

Stoneman, K. G., \& Dickinson, A. M. (1989). Individual performance as a function of group contingencies and group size. Journal of Onganizational Behavior Management, 10, 131-150.

Terborg, J., \& Miller, H. (1978). Motivation, behavior and performance: A closer examination of goal setting and monetary incentives. Joumal of Applied Psychology, 63, 29-39.

Vough, C. F. (1979). Productivity: A practical program for improving efficiency. New York: Amacom.

Yukl, G., Wexley, K., \& Seymore, J. (1972). Effectiveness of pay incentives under variable ratio and continuous reinforcement schedules. Joumal of $\mathrm{Ap}$ plied Psychology, 56, 19-23. 